\title{
A COMPETÊNCIA COMUNICATIVA NA ADMINISTRAÇÃO DISCURSIVA DE ORGANIZAÇÕES
}

\section{COMMUNICATIVE COMPETENCE IN THE DISCURSIVE ADMINISTRATION OF ORGANIZATIONS}

\author{
Clovis Ricardo Montenegro de Lima ${ }^{1}$ \\ Fernanda Kempner-Moreira ${ }^{2}$ \\ Helen Fischer Günther ${ }^{3}$ \\ José Rodolfo Tenório de Lima ${ }^{4}$
}

\begin{abstract}
RESUMO
Introdução: Discute-se a abordagem discursiva da administração das organizações, uma ciência que é embasada em escolhas racionais de fins e de meios, mas que pode (e deve) ter elementos de crítica. Objetivos: Desenvolver uma abordagem discursiva da administração para, adiante de deslocar os fundamentos teóricos, também construir referências para uma gestão humanista e eficaz. Metodologia: Parte-se do contraponto metodológico entre a Teoria do Agir Comunicativo de Habermas e a Teoria de Sistemas de Luhmann para evidenciar o potencial do discurso dos participantes dos sistemas entre si e com o entorno. Resultados: Evidencia-se as possibilidades do agir comunicativo dentro dos sistemas através da linguagem e da argumentação e, notadamente, a problematização e a aprendizagem nas organizações que compõe a competência comunicativa. Para a argumentação é necessário vontade e intencionalidade, mas também a competência comunicativa, que possibilitam a reconstrução racional necessária ao desenvolvimento da administração discursiva. Conclusões: aprofundamos a discussão da administração discursiva e identificamos saídas reconstrutivas para essa prática em prol da humanização das organizações. A competência discursiva fundamenta-se no uso da linguagem e na comunicação que cria vínculos mediante entendimento e acordos e firma o discurso como uma forma especial de interação. A competência comunicativa integra linguagem, gestos e ritualidade.
\end{abstract}

${ }^{1}$ Doutor em Administração e Doutor em Ciência da Informação. Pesquisador do Instituto Brasileiro de Informação em Ciência e tecnologia (IBICT). E-mail: clovismlima@gmail.com

2 Doutoranda do Programa de Pós-Graduação em Engenharia e Gestão do Conhecimento pela Universidade Federal de Santa Catarina (UFSC). Professora da Faculdade Capivari. E-mail: kempnereletrica@hotmail.com

${ }^{3}$ Doutora em Engenharia e Gestão do Conhecimento pela Universidade Federal de Santa Catarina (UFSC). Professora e Pesquisadora na Unisul, Faculdade Tecnológica Senac. Email: fghelen@yahoo.com.br

${ }^{4}$ Doutorando em Sociologia pela Universidade Federal de São Carlos (UFSCar). Professor na Universidade Federal de Alagoas (UFAL). E-mail: jrtlima@gmail.com 
Clovis Ricardo Montenegro de Lima, Fernanda Kempner- Moreira, Helen Fischer Günther, José Rodolfo Tenório de Lima

A Competência comunicativa na administração discursiva de organizações

Descritores: Administração discursiva. Competência Comunicativa. Aprendizagem. Reconstrução Racional.

\section{INTRODUÇÃO}

Neste artigo discute-se a abordagem discursiva da administração das organizações. Esta abordagem parte do contraponto metodológico entre a teoria do agir comunicativo de Habermas e a teoria de sistemas de Luhmann, para evidenciar o potencial do discurso dos participantes dos sistemas, entre si e com o entorno.

A teoria do agir comunicativo de Habermas é não apenas uma opção epistemológica para acessar o mundo da vida, mas também a base de uma ação racional na esfera pública e nos sistemas. Assim, há um forte sentido prático nesta abordagem.

Luhmann afirma que os sistemas são espaços funcionais orientados para fins, onde se reduz a complexidade das ações em relação ao entorno. Esta redução da complexidade se faz através da seleção estratégica de opções pelo sistema, no sentido de orientar as ações para as suas finalidades. Os sistemas são egocêntricos, fechados, buscando apenas os seus interesses.

Luhmann observa que a seleção de opções se processa por uma redução das dinâmicas de comunicação internas aos sistemas. A estruturação dos fluxos de Informação se processa por rigorosa demarcação de competências de fala e de controle dos registros e dos canais de Informação. Isto reduz as possibilidades de interagir comunicativo internamente e com 0 entorno.

A questão que se coloca é, a partir de uma abordagem discursiva, agir comunicativamente no sentido de uma crítica das escolhas do sistema. Os participantes têm suas próprias escolhas. $O$ entorno tem demandas que não devem ser ignoradas pelos sistemas. Enfim, os limites dos sistemas estão sempre em questão.

Esta abordagem traz imediatamente duas indagações. A primeira delas é a possibilidade de agir com argumentos dentro dos sistemas. A redução das dinâmicas da comunicação reduz também os espaços de discurso. Entretanto, 
elas não excluem a dimensão humana dos participantes internos e dos observadores na esfera pública. A fala é o primeiro atributo e expressão desta humanidade.

A segunda questão é quais são as competências requeridas para que participantes dos sistemas façam suas argumentações entre si e com 0 entorno. Entende-se que a crítica das finalidades e dos meios dos sistemas requer vontade e intencionalidade, mas também requer competência comunicativa. Habermas discute esta questão, e pretende-se explorar este tópico.

Estes contrapontos e indagações estão na base teórica do que se designa abordagem discursiva da administração das organizações. A administração faz escolhas racionais de fins e de meios. Ela pode e deve ter elementos de crítica. Este é o nosso território. Uma abordagem discursiva quer não apenas deslocar os fundamentos teóricos, mas construir referências para uma administração humanista e eficaz.

\section{OS SISTEMAS E A REDUÇÃO DA COMUNICAÇÃO NAS ORGANIZAÇÕES}

Luhmann (1997a) considera que as organizações podem ser entendidas como um sistema social autopoiético que tem como base a decisão. Diante disto podemos perceber que o processo de decisão é chave para os sistemas organizacionais, pois é por meio dele em que o sistema irá se desenvolver, respondendo ou não as irritações do ambiente.

Seidl e Becker (2006) afirmam que o entendimento é o ponto central no processo comunicativo da teoria luhmanniana. Diante disto o "entendimento" é compreendido como a maneira pela qual as organizações interpretam as informações da interação com seu ambiente. Tal acontecimento acaba por influenciar seu processo de decisão, até mesmo quando não se decide. As decisões são próprias comunicações, pois as mesmas acabam por gerar novas comunicações.

Entretanto a perspectiva teórica de Luhmann para os sistemas é construída tendo como base o processo de diferenciação de complexidades. 
Esse fato nos faz remeter, inicialmente, a uma discussão sobre complexidade. Neves e Neves (2006) observam que para Luhmann complexidade é a totalidade das possibilidades de acontecimentos que podem ser derivadas das infinitas interações entre elementos (comunicações) também infinitos que existem no ambiente. A complexidade se dá pelo fato de que no ambiente, vários elementos podem assumir inúmeras possibilidades de relações, tendo em vista que não há nenhum fator ordenador e, desta forma, aumenta-se a improbabilidade de operacionalização.

Para propor certo nível de ordem e com isso possibilitar mecanismos de funcionamento, os sistemas aparecem como uma tentativa de redução da complexidade existente no ambiente, por meio do processo de seleção de possibilidades. A complexidade existente no mundo torna, pelo fato da infinita possibilidade das relações, entre infinitos elementos, a sua operacionalização improvável. Para tentar reduzir esta complexidade e se tornar operacionalizável, criam-se espaços que delimitam, por meio da diferenciação de complexidade, um espaço funcional (KUNZLER, 2004).

Este espaço possui mecanismos que o autoreferenciam, ou seja, desenvolvem sua contigencialidade, "o sentido", visando limitar a complexidade existente no ambiente. Esses espaços podem ser descritos como os "sistemas" que são estruturas possuidoras de "sentido", para fazerem frente às complexidades do ambiente (LUHMANN, 1995).

Kunzler (2004, p. 125) destaca que o sistema "[...] deve simplificar a complexidade para conseguir se manter no ambiente. Ao mesmo tempo em que a complexidade do ambiente diminui, a sua aumenta internamente."

O processo seletivo ocorre pelo fato de que o sistema não suporta internalizar toda a complexidade existente no ambiente, pois com isso deixaria de ser sistema. Diante disto há pressão para selecionar determinadas possibilidades. Neste processo de seleção o que os sistemas fazem são justamente importar complexidade para fazer frente a complexidade do ambiente, ou seja, como o próprio Luhmann destaca: apenas a complexidade pode reduzir a complexidade (LUHMANN, 1995).

Em função da racionalidade limitada para responder às diversas possibilidades que o ambiente/entorno possui, tendo em vista a alta 
complexidade existente nele, o sistema, surge como um espaço em que essa complexidade é reduzida, visando justamente a operacionalização. Luhmann (1995) ressalta que o sistema não possui uma representação fiel do ambiente, pois nele o que existe são elementos produzidos por ele mesmo, porque os sistemas são autopoiéticos.

Quando se fala de importar complexidade do ambiente não se refere trazer o fato concreto existente de fora para dentro, mas sim em possibilitar um "entendimento" dos elementos existentes no ambiente externo. Pois é a partir deste entendimento que o próprio sistema irá se auto estruturar. Entretanto, no seu processo evolucionário o sistema ao importar complexidade do ambiente/entorno, a complexidade interna aumenta a um ponto em que se faz necessário uma diferenciação em subsistemas (KUNZLER, 2004).

Luhmann (1995) destaca que essa diferenciação interna é fruto do processo autopoiético. De acordo com Luhmann (2007, p. 341) "La evolución no significa outra cosa sino câmbios de estrutura, y dado que éstes solo pueden efectuarse en el sistema (de modo autopoiético)." Isso nos possibilita entender que a autoprodução (autopoieses), desencadeada pela irritação, dá início ao processo de evolução dinâmica nos sistemas.

Quando há uma irritação, gera-se um tipo de "informação" para o sistema, este que é fruto da diferenciação de complexidade entre o sistema e seu ambiente/entorno, possibilita a iniciação do processo autopoiético do sistema, pois este mecanismo de autoprodução visa neutralizar as "irritações" provenientes do ambiente (RIBEIRO; NEVES, 2005).

Este processo modifica sua estrutura interna, onde subsistemas podem ser criados, visando ampliar as expectativas sobre o ambiente e, desta forma, ampliando sua complexidade interna, pois novos campos seletivos surgem. $O$ processo autopoiético surge como uma evolução dinâmica para o sistema, onde saí de um estágio de menor para um de maior complexidade, em relação ao estado anterior (MATHIS, 1998).

A autopoieses e, consequentemente, a evolução dinâmica do sistema pode ser também influenciada pelo fator tempo. A temporalidade existente no processo comunicativo do sistema para com o ambiente/entorno é aprimorada na escala temporal, pois cria-se uma memória (expectativas), onde ruídos 
anteriores passam a ser enfrentados e as adaptações já realizadas ampliam os campos de possibilidades seletivas (LUHMANN, 2011).

É importante destacar que o sistema se encontra operacionalmente fechado no seu processo de internalização da complexidade (seleção), criação de subsistemas e modificação de expectativas, com relação ao seu ambiente/entorno, pois o ambiente é apenas capaz de irritá-los e não de modificá-lo (LUHMANN, 1997b).

A interação entre os sistemas é mediada pela dupla contingência. A discussão sobre a dupla contingência é um ponto importante da teoria luhmanniana como destacam Vanderstreaten (2002), Siebeneichler (2006) e Korfmann e Kepler (2009). Entretanto seu uso, na perspectiva sistêmica para entendimento da sociedade, foi inicialmente desenvolvida por Parsons.

Luhmann (2016, p. 127) destaca que Parsons se utiliza da perspectiva da dupla contingência para responder a seguinte indagação: Como é possível a ordem social? A resposta parsoniana "[...] inclui a solução do problema da dupla contingência no conceito de ação, mais especificamente, considerando uma orientação normativa com consenso suposto como uma característica imprescindível do agir."

Parsons acredita que a possível incompatibilidade da interação entre ego e alter pode ser solucionada mediante o compartilhamento de valores ou normas. Em outras palavras são os mecanismos simbolicamente compartilhados que mediam e estabilizam a interação. Há complementariedade de expectativas entre os atores envolvidos na interação, ou seja, a expectativa e a ação de cada participante é orientada a partir da expectativa e ação do outro (apud VANDERSTRAETEN, 2002).

A visão parsoniana de solução para o problema da dupla contingência é percebida de forma insuficiente por Luhmann (2016). A perspectiva de "reciprocidade" ou "reflexo de expectativas" não consegue atender de forma satisfatória o atual contexto em que as sociedades complexas se desenvolvem. O modelo de simetria entre os participantes não comporta a autorreferencialidade existente no interior dos sistemas que proporcionam a redução da complexidade.

Vanderstreaten (2002) diz que em Parsons há uma leitura de 
dependência entre os sistemas que interagem, ou seja, o compartilhamento simbólico estabiliza as interações sistêmicas. Porém em Luhmann existe um rompimento com essa visão, contingência é percebida como seleção de possibilidades.

A partir da seleção de possibilidades, Luhmann discute novamente o tema de complexidade, pois no processo seletivo há possibilidades que não são selecionadas e estas, por sua vez poderiam gerar desdobramentos diferentes dos elementos que foram escolhidos. O processo de seleção se ordena, por meio da contingência que cada sistema apresenta e o processo de contingência se traduz em risco e incerteza (NEVES; NEVES, 2006).

A partir deste ponto pode-se compreender, também, que a complexidade é fruto da incerteza das possibilidades (risco) que há no processo seletivo existente e coordenado pela "contingência do sistema". Por contingência do sistema entende-se a forma como o próprio sistema percebe suas interações com outros sistemas.

Rodríguez e Arnold (1991) afirmam que a contingência contribui para a complexidade no momento que seleciona possibilidades e descartam outras. Isso se dá pelo fato de que a contingência existente no sistema está relacionada ao seu "sentido". Pois, caso o "sentido" existente no sistema não compreenda os elementos existentes na interação entre sistema e meio, as possibilidades escolhidas podem não representar aos anseios iniciais do sistema, desencadeando problemas para o sistema.

O sentido é o operador das fronteiras, é o diferenciador do sistema e do ambiente. O sentido adotado pelo sistema é que irá ativar o processo de seleção, onde prescreve o que deve ou não fazer parte do sistema, ou seja, a autorreferencialidade. Ele que irá referenciar determinado elemento, pois o mesmo elemento pode ter diferentes significados (LUHMANN, 1995).

O sistema possui a capacidade de definir os limites perceptivos mais ou menos abertos e permeáveis à outros sistemas, porém deverá ocorrer, internamente regras de seleção com o auxílio de quais temas/informações podem ser aceitas ou não. Luhmann (2016, p. 151) destaca que 
[...]a dupla contingência atua, então, ao mesmo tempo como um facilitador comunicativo e barreira comunicativa; e a resistência de tais limites explica-se pelo fato de a readmissão de contingências completamente indeterminadas pertencer às irrazoabilidades.

Vanderstreaten (2002) afirma que em contraposição a Parsons, Luhmann acredita que a estabilização entre os sistemas não reside em um senso compartilhado, mas primeiro em uma série de interações realizadas ao longo do tempo. As interações que ocorrem na sequência temporal possibilitam uma readequação de expectativas e tais fatos ocasionam as mudanças estruturais dos sistemas.

Cabe destacar que na teoria luhmanniana os sistemas são percebidos como redutores de complexidade e construídos autorreferencialmente, a partir da sua autopoieses. A contingência é condição necessária para o surgimento do sistema, assim como, a dupla contingência é fundamental para a construção e desenvolvimento do sistema.

Neste ponto podemos entender que não há relação de dependência entre os sistemas autônomos que interagem via processos comunicativos. Luhmann (1995) ao afirmar que a comunicação coordena a seletividade dos sistemas, trabalha com a hipótese de que o que possibilita a autopoieses nos sistemas são derivações do processo comunicativo.

A comunicação, na teoria sistêmica de Luhmann, não pode ser entendida como uma simples transmissão de informação, pois a informação só pode ser gerada pelo próprio sistema, tendo em vista que ele é autorreferente, ou seja, irá depender de sua contingência. Por isso para Luhmann comunicação se traduz em: "[...] um processo que sintetiza informação, comunicação e compreensão" (NEVES, 1997, p. 16).

Os sistemas e entorno estabelecem contatos entre si por meio do acoplamento estrutural. No momento em que se estabelece este contato, 0 sistema se abre para observar o seu ambiente/entorno. Este processo de observação (seleção) é regido pelo sentido (contingência) do sistema e, consequentemente, pelo código binário. O processo de observação inicia a comunicação que o sistema desenvolve para gerar informações sobre seu ambiente/entorno. 
Ao processar a interação, o sistema, por já possuir seu sentido, seleciona algumas possibilidades no ambiente/entorno. O mesmo tem expectativas sobre o que irá interpretar ou entender do ambiente. Estas expectativas já são algumas possibilidades selecionadas, dentre estas, algumas serão escolhidas pelo código binário. Entretanto, quando o código binário não consegue interpretar ou gerar informação a partir da interação, temse um ruído, pois surgem novos fatos que não fazem parte do sentido e com isso essa nova "mensagem" se torna uma "irritação". O ruído é interpretado como uma irritação (contingência) do ambiente sobre o qual o sistema deve se reconfigurar, por meio da autopoieses, para fazer frente a esta irritação (KUNZLER, 2004).

Siebeneichler (2006) destaca que na teoria luhmanniana as necessidades de comunicação entre os sistemas não residem no meio linguístico da comunicação (linguagem comum) apreensíveis intersubjetivamente. $\mathrm{Na}$ verdade há uma decisão individualizada sobre o sucesso ou fracasso das "suposições" realizadas autopoieticamente pelos sistemas. A impossibilidade enfatizada pelo autor gerar incompatibilizações de entendimento do ambiente por parte do sistema. O que efetivamente acontece é uma interpretação autorreferente do contato realizado que pode está distorcida da realidade.

A crítica problematizadora pode emergir no entorno das organizações, em função dos seus riscos e das suas externalidades. Abre-se deste modo uma situação limite para os sistemas. De um lado as organizações podem se fechar, mas por outro podem se abrir a crítica. Siebeneichler (2006, p. 50) em sua discussão sobre o sistema imunizador luhmanianno e o mundo da vida habermasiano lança uma questão para a reflexão: É possível sincronizar de alguma forma essas perspectivas totalmente estranhas entre si e geradoras de insegurança?

Uma saída para essa indagação é a ideia de reconstrução discursiva das organizações que têm como mecanismo operacionalizador 0 agir comunicativo e a racionalidade comunicativa. Esse mecanismo tenta ser a "ponte" sincronizadora entre o sistema e o seu entorno, ou seja, tenta reconstruir as ligações que foram desfeitas, a partir do fechamento operacional 
dos sistemas, na redução de complexidade existente no mundo da vida.

As organizações são entendidas por Luhmann (1997) como sistema autopoiético que tem como base a decisão. As decisões são tomadas tendo como referência uma construção racional monológica, pois autorreferencialidade sistêmica não permite a interação comunicativa, na verdade ela rompe com o compartilhamento intersubjetivo. Diante disto as regras ou formas de entendimento que são construídas partem de um pressuposto interno ao sistema.

\section{PROBLEMATIZAÇÃO E APRENDIZAGEM EM ORGANIZAÇÕES}

As organizações constituem-se a partir da redução da complexidade do entorno como forma de conseguir garantir sua sustentabilidade $e$ competitividade. Neste sentido, a dinâmica comunicacional interna deve ser estruturada em fluxos orientados, de forma que o agir comunicativo assume papel de mediador das relações entre educadores e educandos, enquanto que o conhecimento "[...] se torna o mediador da comunicação e do diálogo entre os que aprendem" (LIMA, KEMPNER, TISCOSKI, 2010, p. 12).

O uso da teoria do agir comunicativo (TAC) na área de estudos organizacionais tem sido crescente por abordar diretamente aspectos centrais da teoria organizacional. A TAC surge tendo por referência a mudança no paradigma da filosofia da consciência para o paradigma da linguagem. Isso remete à ideia de interação entre os membros da organização, ou mesmo entre organizações. Essa interação parte de um processo intersubjetivo de troca de significados, ou seja, a comunicação é dialógica (VIZEU, 2005).

Agostinho (2003) ressalta o sistema de comunicação como mediador entre a organização e seu ambiente. Como um sistema complexo adaptativo, a organização necessita da comunicação para interagir com o ambiente e com seus próprios elementos agentes. A comunicação auxilia o fluxo de informações a respeito de seu desempenho e das condições do ambiente.

Como conceitos-chave dos sistemas adaptativos complexos, Agostinho (2003) expõe a autonomia, a cooperação, a agregação e a auto-organização. Todos estes conceitos se inter-relacionam, e a comunicação surge como um dos elementos que proporcionam esta inter-relação. 
A autonomia dos sistemas complexos adaptativos é auxiliada pela comunicação, possibilitando o aumento de uma de suas vantagens às organizações: 0 aprendizado.

A comunicação sofisticada e a capacidade de prever teoricamente as consequências de seus atos, sem que seja necessário experimentar uma situação real, resultam em uma enorme capacidade de aprendizado. Contudo, tamanho potencial só é realizado quando é permitido ao indivíduo colocar seu julgamento em ação (AGOSTINHO, 2003, p. 9).

É este poder de ação que a Teoria de Agir comunicativo ressalta. Tendo como centro da discussão o mundo da vida, este se torna o horizonte no qual os agentes comunicativos, ou seja, os indivíduos dotados de autonomia se movem (HABERMAS, 1987a). Esta autonomia proporciona aos indivíduos e à organização o aprendizado e a solução de conflitos através da discussão entre os atores autônomos (AGOSTINHO, 2003).

A cooperação é fator crítico para gestões que pretendam aproveitar 0 conhecimento contido nas organizações. Indivíduos que cooperam buscam benefício próprio através do benefício coletivo (AGOSTINHO, 2003). A interação entre os indivíduos se dá com o auxílio da comunicação, ou seja, indivíduos que discutem tem maior probabilidade de cooperar.

Habermas (1987b) ressalta que um dos componentes estruturais do mundo da vida é a sociedade, entendida como as ordenações legítimas através das quais os participantes da interação regulam suas pertenças a grupos sociais, assegurando a cooperação. E essa cooperação requer uma relação de diálogo autêntico, relação esta que levará ao conhecimento necessário para as organizações. Nesse sentido, os participantes deixam de ser sujeitos passivos para tornarem-se sujeitos ativos e criadores, onde $o$ ato de conhecer encontrase mediatizado pelo objeto a ser conhecido (LIMA, KEMPNER, TISCOSKI, 2010).

Agostinho (2003) retrata a organização como uma agregação, identificado por seus objetivos e competências globais em torno dos quais agrega-se indivíduos que contribuem para a competência do todo com suas habilidades e conhecimentos. Trata-se dos subsistemas da organização. "Quanto mais complexo o sistema, mais níveis de organização serão encontrados" (AGOSTINHO, 2003, p. 10). 
Entretanto, os níveis hierárquicos não precisam ser necessariamente tratados de maneira autoritária. Esses níveis hierárquicos exigem um maior poder de comunicação, para que a informação flua de maneira a contribuir para o crescimento da organização e não tolher a autonomia dos indivíduos. A agregação possibilita que a organização suporte as pressões de seleção que existem em seu ambiente (AGOSTINHO, 2003).

A intersubjetividade nos processos de entendimento acontece na forma de aconselhamento instituído na organização e nas redes de comunicação, que funcionam como sensores que reagem à pressão de situações-problema. Essas redes utilizam-se do poder comunicativo não para dominar, mas para direcionar a administração para determinados canais. Neste sentido, o discurso argumentativo surge como facilitador da cooperação, proporcionando igualdade de direito comunicativo (LIMA et al, 2009).

Agostinho (2003, p. 11) ressalta como um dos aspectos mais interessantes das organizações sociais humanas o fato de termos a capacidade de escolher como os sistemas complexos adaptativos devem operar na prática. Isso acontece pela capacidade do gestor de identificar pontos com maior ou menor efeito multiplicador, direcionar recursos adequadamente e criar condições mínimas para que a organização funcione adequadamente. Eis a auto-organização.

O potencial auto-organizante das organizações necessita da autonomia dos indivíduos, para que os mesmos possam utilizar suas capacidades a favor da organização; necessita de relações cooperativas, caso contrário tem-se o caos. A autonomia e as relações cooperativas, importantes para criar um ambiente propício para a auto-organização, necessitam de aspectos comunicativos para acontecerem nas organizações. Os gestores devem se esforçar para que "o sistema se auto-organize, não só abrindo e fortalecendo canais de comunicação multidirecionais, como também ampliando a capacidade de percepção, interpretação e resposta a todos os tipos de feedback" (AGOSTINHO, 2003, p. 12).

Ao permitir que o sistema entre em contato com seu entorno, ao mesmo tempo em que se isola dele, a comunicação transforma-se em operação básica 
paradoxal, além de os sistemas disporem de uma linguagem com fundo semântico (LIMA et al., 2009).

Tendo como pano de fundo o mundo da vida, constituindo o horizonte, os recursos e o contexto para o entendimento através da linguagem, Habermas privilegia as ações comunicativas realizadas por linguagem comum. Ressalta que esses processos dependem de discursos e argumentos destinados a resgatar pretensões de validade. Interpreta a intersubjetividade como uma comunicação, ou interação, entre atores capazes de falar e agir (SIEBENEICHLER, 2006).

Morgan (1996) afirma que estabelecer um diálogo com a situação que se está tentando compreender é o único modo de realizar julgamentos equilibrados. Desenvolver a arte da leitura das situações, da análise crítica e da avaliação é um novo modo de pensar, no qual se aprende a reconhecer pontos importantes e as ideias cruciais. Neste caso, a ação comunicativa surge como uma ferramenta de apoio à função gerencial e ao sucesso das organizações.

Toffler (1985) ressalta que as propostas participativas são a única alternativa para obter eficiência no novo ambiente em que as organizações se encontram. Ele afirma que a hierarquia vertical está perdendo sua eficiência, enquanto os responsáveis pela decisão se confrontam com tipos cada vez mais variados de problemas, complexas decisões técnico-econômicas, responsabilidades políticas, culturais e sociais. A consequência disto é que as decisões atualmente devem ser tomadas em níveis cada vez mais baixos da organização. "Assim, as demandas de participação não fluem do ideológico para a política, mas sim do reconhecimento de que o sistema, conforme está estruturado hoje, não pode sem isso reagir eficientemente ao meio em rápida transformação" (TOFFLER, 1985, p. 148).

González de Gómez (2009) afirma que a ação comunicativa é uma forma de interação social em que o plano de ação de vários agentes - dentro das organizações ou entre organizações - são coordenados pelo intercâmbio de atos comunicativos, ou seja, através do uso da linguagem verbal ou de expressões extraverbais correspondentes, sempre orientadas para 0 entendimento - o que Habermas chama de Verständigung. Quando os participantes de uma ação comunicativa colocam demandas de validade que 
podem ser negadas ou aceitas, estabelece-se uma relação reflexiva atormundo.

O sucesso do intercâmbio comunicativo e da interação depende da habilidade de todos os participantes em responder a uma demanda de validade relacionada a algo enunciado. A principal consequência desta concepção é que os participantes da ação comunicativa só alcançam seus objetivos se cooperarem e se reconhecerem uns aos outros. Sendo assim, o agir comunicativo "é um modo de uso comunicativo da linguagem, na vida quotidiana, na qual os participantes levantam, aceitam ou rejeitam pretensões de validade" (GONZÁLEZ DE GÓMEZ, 2009, p. 124).

O Discurso - que pode ser grafado em maiúsculo por ser para Habermas um conceito - trata-se de uma forma de comunicação onde são tematizadas as pretensões de validade constituídas nos processos de busca do entendimento mútuo, que tornaram-se problemáticas e que precisam ser examinadas à luz de processos argumentativos. No Discurso extrapola-se o contexto da ação; é preciso apresentar argumentos que justifiquem ou rejeitem as pretensões de validade problematizadas (GONZÁLEZ DE GÓMEZ, 2009).

Habermas acredita que a resolução de problemas é o mecanismo central dos processos de aprendizagem. E este processo de aprendizagem passa pela linguagem. Ao gerar uma rede de significados intersubjetivamente compartilhados, a ação comunicativa instaura-se como um novo modelo teórico que torna viável, através da racionalidade comunicativa, uma análise crítica das relações sociais e produtivas, apresentando-se como força dinamizadora que impulsiona para uma visão mais abrangente da realidade, em que o fim último está na possibilidade de construir soluções comuns e acordos que respeitam o melhor e mais viável argumento, intersubjetivamente reconhecido e aceito por todos (BOLZAN, 2005).

Vale trazer à discussão as semelhanças entre Habermas e Paulo Freire em diversos aspectos. Para ambos o ser humano é o centro das reflexões e a linguagem tem papel fundamental na construção social e na aprendizagem. Para Habermas a comunicação se dá pelas relações sociais, assim como Freire, para o qual a comunicação é uma co-participação dos atores sociais em busca de criar conhecimento juntos (LAROCCA; MAZZA, 2003). 
Tanto a ação comunicativa de Habermas como a ação dialógica de Freire demandam uma nova racionalidade baseada na comunicação e no entendimento entre os atores envolvidos (MEDEIROS; NORONHA, 2015). Essa comunicação deve partir da problematização da vida real para a solução de problemas por meio da participação dos envolvidos como forma de mudar e melhorar o entorno para todos.

Nassar (2006) ressalta a importância da comunicação e da participação dos atores envolvidos para que a organização atinja suas expectativas de imagem, conceito e bons resultados. Salienta a comunicação deve ser desenvolvida como instrumento de gestão, capaz de orientar o relacionamento com os atores, permitindo que estes participem e haja envolvimento de sentidos e atitudes das pessoas.

Neste sentido, a linguagem tem papel emancipatório, sem a qual a própria aprendizagem não consegue prosperar.

O discurso tem papel ativo na transformação das organizações, valorizando e viabilizando a expressão e a comunicação entre os que participam dos processos produtivos. São a ampliação das expressões das perspectivas e a viabilidade da comunicação que vão proporcionar a aprendizagem a partir dos próprios processos produtivos (LIMA; KEMPNER; TISCOSKI, 2010, p. 14).

Habermas, em sua teoria da ação comunicativa, pressupõe que o sujeito envolvido na construção de um plano de ação precisa entender-se com os outros atores envolvidos. Este processo apresenta caráter comunicativo, que deve ser mediado pela linguagem, onde os atores procuram entender-se sobre determinado assunto. Este entendimento passa pelo processo de levantamento comunicativo de pretensões de validade reconhecidas por todos, passíveis de julgamento objetivo, problematizadas e debatidas, em cima das quais se estabelecerá o consenso, ou seja, a escolha do melhor argumento (HABERMAS, 1987a).

\section{COMPETÊNCIA COMUNICATIVA E RECONSTRUÇÃO RACIONAL}

A ação comunicativa é mediada pela linguagem em busca do entendimento e do consenso. A qualidade da ação comunicativa está 
embasada nas competências comunicativas dos agentes no sistema, dentre as quais está a argumentação dentro do sistema e entre este e o entorno.

A competência discursiva se refere à capacidade de interação que representa o entendimento do grupo. O principal olhar que se dá aqui à interação é a interação mediada pela linguagem, de modo que a competência comunicativa é desenvolvida notadamente por meio da linguagem e de suas funções no sistema.

Habermas (2004) considera que a linguagem se presta tanto à comunicação como à representação e, o proferimento linguístico é, ele mesmo, uma forma de agir que serve ao estabelecimento de relações interpessoais. A partir dessas relações são firmadas diferentes e diversas camadas de vínculos pautados na competência discursiva e que que acabam por compor organicamente os sistemas.

Quando falamos em uma perspectiva linguística na competência comunicativa, compreende-se que ela não se confunde com habilidade, e também não é uma substância. Trata-se de uma capacidade que é difusa e, no sistema, há fatos e normas e, entre os fatos e as normas, existe uma mediação. E é nesse lugar da mediação que entra a linguagem e uma competência de agir, de se comunicar. Essa competência que é linguística por baixo e é discursiva por cima.

A língua não é a propriedade privada de um indivíduo, mas cria um contexto de sentido intersubjetivamente partilhado, corporificado em expressões culturais e práticas sociais. Cada língua só se desenvolve socialmente, e o homem só se compreende a si mesmo ao testar a compreensibilidade de suas palavras junto a outras pessoas (HABERMAS, 2004).

O enraizamento da competência comunicativa está na linguagem e, por isso, trazemos à discussão as três funções da linguagem que Habermas (2004) resgata de Humboldt. São elas: (1) a função cognitiva de formar pensamentos e representar fatos; (2) a função expressiva de exprimir sentimentos e suscitar sensações; por fim, (3) a função comunicativa de comunicar algo, levantar objeções e produzir acordos. A representação da interação dessas funções, do 
ponto de vista pragmático de um entendimento mútuo entre interlocutores, está na conversação, ou seja, no desenvolvimento da competência comunicativa.

A linguagem é constitutiva da personalidade (formação da identidade), que é integradora socialmente, isto é, que é socializadora, pois integra o indivíduo aos grupos e, é mediadora da relação indivíduo-mundo da vida. A linguagem tem um elemento de socialização que constitui a sociedade, firmando o poder constituinte da linguagem e, por conseguinte, exercendo uma função de criação de vínculo entre os diferentes participantes e destes com 0 sistema e com o seu entorno.

A interação, considerando a função cognitiva da linguagem, se dá na "[...] conexão com discursos em que os participantes podem oferecer respostas e contradizer" (HABERMAS, 2004, p. 65). Isto é, a linguagem não é só para interpretar, e representar, a linguagem tem uma função de criação de vínculo social, estabelecendo ao mesmo tempo uma relação intersubjetiva entre quem fala e quem escuta e uma relação objetiva com o mundo.

A competência comunicativa é vista, portanto, como capacidade fundamental da interação humana e da significação da vida e da realidade. A maneira realizar tais interações - sejam mundo objetivo, mundo social ou mundo subjetivo - é por meio da linguagem, pois assim objetivamos e organizamos logicamente a complexidade de questões originadas nas (e no intercâmbio das) três esferas ontológicas (VIZEU, 2003).

Depreende-se, então, que a linguagem é constitutiva da sociedade, ou seja, a linguagem faz parte da construção da sociedade e, por conseguinte, a sociedade não antecede a linguagem e esta é que tece vínculos sobre os quais se erige o sistema. Afinal, uma pessoa entende-se com outra sobre alguma coisa no mundo e, o proferimento linguístico - como representação e como ato comunicativo - aponta em duas direções ao mesmo tempo: o mundo e o destinatário (HABERMAS, 2004).

Utilizar a linguagem para fins de entendimento se relaciona a um saber intuitivo que os indivíduos socializados possuem e que se mostra como uma competência comunicativa adquirida pela inserção no mundo da vida e que os indivíduos utilizam na ação comunicativa (SILVA; LIMA; FERNANDES, 2013). 
No cotidiano não podemos usar a linguagem sem que estejamos agindo. A própria fala se realiza no modo de atos de fala que, por sua vez, pertencem a contextos de interação e são entrelaçados com ações instrumentais. Como atores, ou seja, como sujeitos interagentes e interventores que somos, estamos em contato com as coisas sobre as quais podemos fazer enunciados (HABERMAS, 2004).

As ações são de tipo social ou não-social. O agir social consiste ou (1) na interação normativamente regida entre sujeitos que agem pela comunicação ou (2) na tentativa dos antagonistas de exercerem uma influência estratégica mútua. Já o agir instrumental está enlaçado em contextos de ação social e serve a intervenções finalísticas no mundo de coisas. Esses tipos de agir regido por regras constituem, então, apenas um recorte dos tipos de comportamento regido por regras (HABERMAS, 2004).

A competência comunicativa também é uma competência ritualística, é uma competência gestual e é uma competência linguística. Acima de tudo trazemos uma forma específica de competência linguística que é a competência comunicativa (a linguagem como elemento da competência comunicativa). Em outras palavras, a linguagem para se comunicar (que não é linguagem estética, nem estratégica) compõe um tipo específico de competência comunicativa que é a competência discursiva, porque falamos de um gestor, de um administrador e de uma racionalização normativa.

Webler e Tuler (2000) citados por Vizeu (2003, p. 13) trazem sete princípios para essa competência discursiva. $O$ acesso ao processo de decisão (presença física do participante no debate e a possibilidade de falar e ser ouvido) e o poder para influenciar o processo e seus resultados (a competência discursiva somente pode ser considerada como autêntica se puder ser efetivada nos resultados). A interação construtiva facilitada por meio (a) de estruturas adequadas (posição dos participantes no espaço físico, tempo de fala, por exemplo e (b) de comportamento pessoal (postura pessoal que facilita a confiança e a crítica construtiva, a exemplo de tolerância e paciência). O acesso à informação e à sua análise adequada (não tendenciosa ou parcial) e, por fim, a habilitação de condições necessárias para processos futuros, com o intuito de aproveitar as deliberações que possam ser utilizadas sem nenhum 
Clovis Ricardo Montenegro de Lima, Fernanda Kempner- Moreira, Helen Fischer Günther, José Rodolfo Tenório de Lima

A Competência comunicativa na administração discursiva de organizações

comprometimento e de modo a não gerar novos processos de discussão e negociação.

Considerando a predominância da redução do mundo da vida pelo sistema, e que é necessário criar espaço para reaprender sobre si mesmo, sobre a interação com o ser dos outros e sobre a manifestação livre desse entrelaçamento de linguagens e construção social, a competência comunicativa demanda um processo de aprendizagem.

Aprender significa repensar, assumir uma atitude crítica diante do mundo. O processo de aprendizagem, como ação cultural, é um ato de conhecimento em que quem aprende assume o papel de sujeito cognoscente em diálogo com quem ensina, que é sujeito cognoscente também (FREIRE, 1981).

Habermas (1989) orienta que o processo de aprendizagem é acompanhado pelo desenvolvimento moral do indivíduo que, por sua vez, envolve transformação e diferenciação das estruturas cognitivas, em que o indivíduo que aprende consegue no presente resolver melhor uma espécie de problemas do que o fazia anteriormente no passado (por exemplo, consegue desenvolver uma solução consensual de conflitos de ação moralmente relevantes). Fazendo isso a pessoa em crescimento compreende o seu próprio desenvolvimento moral como um processo de aprendizagem, uma vez que deve poder explicar até que ponto estavam errados os juízos morais que considerava corretos anteriormente.

$\mathrm{O}$ autor ainda esclarece que as estruturas cognitivas que subjazem à faculdade de julgar moral não devem ser explicadas nem primariamente por influências do mundo ambiente, nem por programas inatos e processos de maturação, mas, sim, como o resultado de uma reorganização criativa de um inventário cognitivo pré-existente e que se viu sobrecarregado por problemas que reaparecem insistentemente (HABERMAS, 1989).

Tal reorganização criativa se manifesta mais livremente quando as reflexões socialmente distribuídas podem ser comunicadas e são providas de significado situacional. É esperado que a interação mais recente interaja com as reflexões que ainda não foram comunicadas, gerando uma nova variação e, ao gerar essa nova variação, o sistema se impulsiona (LEYDESDORFF, 2000). 
Podemos interpretar que tal impulsionamento se dá mediante 0 aprendizado que advém do desenvolvimento da competência comunicativa e é necessário para a resolução de problemas comumente presentes nos sistemas de complexidade forçosamente reduzida. Torna-se necessário repensar as ações mediadas pela linguagem de tal modo para que possibilite a reconstrução da racionalidade ali preponderante.

Os participantes assumem, então, desde o começo da ação, o papel de sujeitos criadores. $O$ ato de conhecimento que leva a sério o problema da linguagem deve ter como objeto a ser desvelado as relações dos seres humanos com seu mundo. A análise destas relações começa a aclarar 0 movimento dialético que há entre os produtos que os seres humanos criam ao transformarem o mundo e o condicionamento que estes produtos exercem sobre eles. $\mathrm{O}$ ato de conhecer envolve movimento dialético que vai da ação à reflexão sobre ela e desta a uma nova ação, essencial à reconstrução da racionalidade. $O$ diálogo engaja ativamente a ambos os sujeitos ao ato de conhecer (FREIRE, 1981).

Essa configuração nos fornece oportunidades para construir nichos dentro do sistema com opções para melhorar a qualidade de vida como decorrência do ajuste, por exemplo, das competências comunicativas às exigências da cultura comunicada (LEYDESDORFF, 2000). As práticas administrativas podem, então, serem reconstruídas a partir da linguagem, da competência discursiva e do processo de aprendizagem decorrente.

Cabe destacarmos, conforme relatam Repa e Nobre (2012a), que a ideia de reconstrução é central no trabalho habermasiano. De acordo com os autores o projeto reconstrutivo de Habermas pretende elucidar as regras e os processos sociais em que objetos simbólicos emergem e ganham sentido nas relações sociais. Reconstruir, no sentido habermasiano, significa refletir sobre as regras que têm de ser supostas para que seja possível a própria compreensão do sentido que é construído social e simbolicamente.

A resposta de Habermas à ideia de emancipação, que caracteriza o campo crítico de sua construção teórica, é o mecanismo reconstrutivo de modo que os principais componentes da teoria reconstrutiva da sociedade podem 
ganhar seu sentido à luz do conceito de ação e de racionalidade comunicativa (REPA; NOBRE, 2012a).

A reconstrução discursiva dos sistemas organizacionais significa buscar refletir sobre as regras que pautam o processo decisório e que têm de ser supostas como princípio para a compreensão do sentido. São essas regras, estruturas e processos que constituem a racionalidade imanente aos objetos simbólicos, a racionalidade que eles reivindicam por si mesmos para que possam ter sentido. A reconstrução racional de estruturas profundas, geradoras das decisões, permite investigar a racionalidade própria das regras usadas em um determinado momento pelo sistema.

A base reconstrução discursiva das organizações está na reconstrução "procedimental" proposta por Habermas em Direito e Democracia. Nobre e Repa (2012b, p. 40) destacam:

[...] Habermas não apenas reconstruiu a racionalidade do direito e do estado democrático de direito, mas fez o de tal maneira que propôs um paradigma alternativo não só para a autocompreensão dessas instituições, mas igualmente para o seu funcionamento concreto [...] (grifo nosso).

Silva e Melo (2012), por sua vez, destacam que a reconstrução, na perspectiva procedimental, discute a tensão entre facticidade e validade que se observa tanto interna quanto externamente ao sistema direito na legitimação de suas normas na sociedade plural. Para os autores, Habermas indica, na sua proposta, que essa tensão tem de ser reconstruída, pois guarda possibilidades de uma democratização radical da vida social. Esse fato implica em uma submissão constante das instituições (sistemas) existentes à crítica e à transformação reflexiva, superando, desta forma, a imunização existente nos seus conteúdos normativos e formas de funcionamento.

É a partir desta visão, reflexiva e crítica, que se pensa a reconstrução discursiva das organizações, ou seja, propor um mecanismo em que as organizações se abram para a escuta dos seus críticos e, desta forma, problematize sobre sua interação com o entorno. A abertura a crítica é o caminho para ampliar o campo perceptivo das organizações, pois a partir da construção de um entendimento baseado na discursividade, há uma tentativa de estabelecimento de uma "ponte" com a complexidade excluída e existente 
no mundo da vida. A reconstrução se propõe, conforme apontam Silva e Melo (2012, p. 135), a uma "[...] diluição de naturalizações e engessamentos indevidos das formas institucionais" que impedem a percepção multidimensional.

O procedimento adotado para a reconstrução discursiva das organizações está fundamentado em uma atitude que tem o processo comunicativo como chave. Essa proposta rompe com a atitude objetivante, típica de um observador de regularidades empíricas. Neste caso os atores agem comunicativamente buscando encontrar uma definição comum para sua situação, assim como, em se entender sobre temas e planos de ação existentes interna e externamente a organização.

Silva e Melo (2012) sinalizam que a reconstrução procedimental habermasiana possui dois ambientes de atuação, um interno e outro externo. A reconstrução interna se volta aos modos de funcionamento do sistema, procurando recompor a tensão entre suas expectativas normativas de legitimação e a facticidade de sua forma impositiva. Nesse caso busca-se reconstruir discursivamente a normatividade sistêmica, tendo participação direta dos atores envolvidos. Essa visão é importante para discutirmos a validade de normas criadas para serem cumpridas pelos sujeitos organizacionais.

A construção discursiva é uma tentativa de reduzir a tensão existente entre a positividade das normas e o reconhecimento validativo de seus executores. O grande objetivo desta proposta de reconstrução é uma autocompreensão sistêmica, que seja construída dialogicamente entre seus participantes. A reconstrução interna remete a processos deliberativos que transcendem os discursos herméticos dos operadores sistêmicos, incluindo a possibilidade de participação da comunidade organizacional em seu todo. A partir desta reconstrução reconhece-se a insuficiência de os debates circunscritos às instâncias formais de tomada de decisão cumprirem sozinhos as exigências de uma formação discursiva da opinião e da vontade da comunidade sistêmica. Há, como forma alternativa, a necessidade de se manterem os processos deliberativos mais densos e plurais, os quais tomam lugar à margem de suas fronteiras institucionais. 
A reconstrução procedimental externa é a proposta de sincronização com o entorno sistêmico, ou seja, a abertura do sistema para a complexidade existente no mundo da vida. Para operacionalização deste procedimento é fundamental o reconhecimento e predisposição para a interação com as esferas públicas que habitam o entorno do sistema.

Nas sociedades modernas forma-se uma consciência comum difusa baseada em projetos polifônicos e opacos de totalidade. Tal consciência pode concentrar-se e articular-se de maneira mais clara com o auxílio de temas específicos e de contribuições ordenadas que são condensados em uma esfera pública. Nas esferas públicas, os processos de formação da opinião e da vontade são institucionalizados e, por mais especialização que possam ser, estão orientados para a difusão e à interpenetração.

\section{CONSIDERAÇÕES FINAIS}

A linguagem representa e comunica, mas ela também constrói vínculos sociais. Aqui há uma interação entre cognição e construção da sociedade. A linguagem em uso faz parte das dialéticas do ser social, cria personalidades e identidades, integra socialmente aos grupos e socializa. A linguagem nos produz dentro do mundo da vida. Habermas falava de uma distorção sistemática da linguagem.

A questão é o uso da linguagem nestes espaços de complexidade reduzida que são os sistemas, as organizações. A redução em relação ao entorno se processa pelo agir estratégico. A estruturação dos fluxos de Informação interfere nas possibilidades do agir comunicativo. Entretanto, os participantes dos sistemas também estão no mundo da vida. A moralidade, o direito e a política afetam e são afetados por esses pelos participantes dos sistemas.

Uma forma especial de agir comunicativo - o discurso - pode ser uma opção racional e pragmática para a administração das organizações. Esta opção torna-se necessária quando se critica as finalidades ou se quer melhorar ou inovar a agenda dos sistemas.

A aprendizagem dos participantes das organizações parte da problematização e permite a reconstrução racional a partir dos seus acordos. 
Clovis Ricardo Montenegro de Lima, Fernanda Kempner- Moreira, Helen Fischer Günther, José Rodolfo Tenório de Lima

A Competência comunicativa na administração discursiva de organizações

Aprender requer descentrar-se, colocar-se no lugar do outro. Este processo vale para os participantes, uns com os outros. Há que fazer também a crítica da autorreferência do sistema.

$\mathrm{O}$ artigo usou o recurso de contrapor a teoria do agir comunicativo de Habermas à teoria de sistemas de Luhmann. A teoria luhmanniana sugere que as organizações são espaços de redução da complexidade em relação ao entorno para execução de atividades orientadas a fins. Discutiu-se as possibilidades de agir comunicativo dentro dos sistemas, assim como indagar a importância de se abrir a organização para o mundo da vida.

A redução da complexidade da interação mediada pela linguagem e a estruturação dos fluxos de informação nos sistemas parecem interditar o agir em função de competências funcionais.

A crítica neste trabalho quer ampliar a discussão como para o desenvolvimento da administração discursiva das organizações. Espera-se com isso contribuir para os estudos críticos no âmbito dos estudos organizacionais, assim como, lançar luz para possíveis saídas "reconstrutivas" da prática administrativa. A humanização das organizações se faz a partir da intersubjetividade dos seus participantes. .

A competência comunicativa destes participantes parte da capacidade de uso da linguagem, e inclui representar as coisas e os fatos, comunicar-se com o outro e criar vínculos. A criação de vínculos requer entendimento e acordos. O discurso é uma forma especial de interação mediada pela linguagem. É um jogo argumentativo. A competência comunicativa integra linguagem, gestos e ritualidade.

\section{REFERÊNCIAS}

AGOSTINHO, M.C.E. Administração Complexa: revendo as bases científicas da administração. RAE eletrônica, São Paulo, v. 1, n. 2, jan./jun., 2003.

Disponível em: <http://www.rae.com.br/artigos/1254.pdf>. Acesso em: 29 set. 2008.

BOLZAN, J. Habermas: razão e racionalização. ljuí: Ed. Unijuí, 2005.

FREIRE, P. Ação cultural para a liberdade: e outros escritos. 5. ed. Rio de Janeiro: Paz e Terra, 1981. 
GONZÁLEZ DE GÓMEZ, M. N. Habermas, informação e argumentação. In: PINZANI, A.; KORFMANN, M.; KEPLER, F. K. A contingência das ordens: a literatura como observação entre o atual e o potencial. Gragoatá, Nitéroi, v. 14, n. 27, p. 97-115, jun. 2009.

KORFMANN, M.; KEPLER, F. K. A contingência das ordens: a literatura como observação entre o atual e o potencial. Gragoatá, Niterói, v. 14, n. 27, p. 97115, jul./dez. 2009.

KUNZLER, C. de M. Teoria dos sistemas de Niklas Luhmann. Estudos de Sociologia, Araraquara, v. 16, p. 123-136, 2004.

HABERMAS, J. Teoria de la acción comunicativa, v. 1. Madrid: Taurus, 1987.a

HABERMAS, J. Teoria de la acción comunicativa, v. 2. Madrid: Taurus, 1987.b

HABERMAS, J. Consciência moral e agir comunicativo. Rio de Janeiro: Tempo Brasileiro, 1989.

HABERMAS, J. Verdade e justificação: ensaios filosóficos. São Paulo: Edições Loyola, 2004.

LAROCCA, L. M.; MAZZA, V. A. Habermas e Paulo Freire: referenciais teóricos para o estudo da comunicação em enfermagem. Revista Gaúcha de Enfermagem, Porto Alegre, v. 2, n. 24, p. 169-176, ago. 2003.

LEYDESDORFF, L. Luhmann, Habermas and the Theory of Communication. Systems Research and Behavioral Science, v. 17, n. 3, p. 273-288, 2000.

LIMA, C. M.; KEMPNER, F.; TISCOSKI, G. P.; Discurso e Aprendizagem em Organizações Complexas. In: Encontro da Associação Nacional de Pósgraduação e Pesquisa em Administração, 34, 2010. Anais...Rio de Janeiro: ANPAD, 2010.

LIMA, C. R. M. et al. Agir comunicativo, colaboração e complexidade nas organizações. Datagramazero: Revista da Ciência da Informação, Rio de Janeiro, v. 10, n. 3, p. 1-18, jan. 2009. Disponível em:

<http://dgz.org.br/jun09/Art_06.htm>. Acesso em: 27 maio 2018.

LUHMANN, N. La sociedad de La sociedad. Ciudad de México. Editora Herder, 2007.

LUHMANN, N. Novos desenvolvimentos na teoria dos sistemas. In: NEVES, C. E. B.; SAMIOS, E. M. B. Niklas Luhmann: a nova teoria dos sistemas. Porto Alegre: UFRGS, 1997b.

LUHMANN, N. Social systems. Stanford: Stanford University Press, 1995. 
LUHMANN, N. Introdução à Teoria dos Sistemas. 3. ed. Petropólis: Vozes, 2011.

\section{LUHMANN, N. Organización y decisión. Autopoieses, acción y entedimiento comunicativo. México: Anthropos, 1997a.}

LUHMANN, N. Sistemas sociais: esboço de uma teoria geral. Petrópolis: Vozes, 2016.

MATHIS, A. O conceito de sociedade na teoria dos sistemas de Niklas Luhmann. In: Associação Nacional de Pós-Graduação e Pesquisa em Ciências Sociais, 22, 1998. Anais eletrônicos... Caxambu: ANPOCS, 1998. Disponível em: <http://simaocc.home.sapo.pt/e-biblioteca/pdf/ebcc_mathis-conceito.pdf>. Acesso em: 05 dez. 2008.

MEDEIROS, A. M.; NORONHA, N. M. Ação comunicativa e ação dialógica: diálogos entre Jürgen Habermas e Paulo Freire no âmbito da "esfera pública". In: Congresso Nacional de Educação, 2, 2015. Anais... Campina Grande: CONEDU, 2015, v. 2. p. 1-12.

MORGAN, G. Imagens da Organização. São Paulo: Atlas, 1996.

NASSAR, M.R.F. O papel da comunicação nas organizações de saúde: oportunidades e desafios. In: Congresso Brasileiro de Ciências da Comunicação, 29, 2006. Anais... Brasília: INTERCOM, 2006.

NEVES, C. E. B. Niklas Luhman e sua obra. In: NEVES, C. E. B.; SAMIOS, E. M. B. Niklas Luhmann: a nova teoria dos sistemas. Porto Alegre: UFRGS,1997.

NEVES, C. E. B.; NEVES, F. M. O que há de complexo no mundo complexo?: Niklas Luhmann e a Teoria dos Sistemas Sociais. Sociologias, Porto Alegre, n. 15, p. 182-207, jan./jun. 2006.

NOBRE, M.; REPA, L. Breve Apresentação. In: NOBRE, M.; REPA, L. Habermas e a reconstrução: sobre a categoria central da teoria crítica habermasiana. Campinas: Papirus, 2012a. p. 7-11.

NOBRE, M.; REPA, L. Introdução - reconstruindo Habermas: etapas e sentido de um percurso. In: NOBRE, M.; REPA, L. Habermas e a reconstrução: sobre a categoria central da teoria crítica habermasiana. Campinas: Papirus, 2012b. p. 13-41.

RIBEIRO, A. M. M.; NEVES, F. M. A conformação dos grupos de pesquisa em biotecnologia da cana de açúcar na região norte-fluminense: a perspectiva do "novo sistemismo". Ciências Sociais Unisinos, São Leopoldo, v. 41, n. 3, p.171-182, set./dez. 2005. 
ROGRÍGUEZ, D.; ARNOLD, M.Sociedad y Teoría de sistemas. Santiago de Chile: Editorial Universitaria, 1991.

SEIDL, D.; BECKER, K. H. Organizations as distinction generating and processing systemas: Niklas Luhmann's contribution to oragnizacion studies. Organization, London, v. 1, n. 13, p. 9-35, abr. 2006.

SIEBENEICHLER, F. B. O direito das sociedades pluralistas: entre o sistema imunizador luhmanniano e o mundo da vida habermasiano. In:

SIEBENEICHLER, F. B. (Org.). Direito, moral, política e religião nas sociedades pluralistas. Entre Apel e Habermas. 1. ed. Rio de Janeiro: Tempo Brasileiro, v. 1, p. 39-60, 2006.

SILVA, F. G.; MELO, R. Crítica e reconstrução em direito e Democracia. In: NOBRE, M.; REPA, L. Habermas e a reconstrução: sobre a categoria central da teoria crítica habermasiana. Campinas: Papirus, 2012. p. 135-167.

SILVA, F. M. S.; LIMA, C. M; FERNANDES, G. C. Competência comunicativa: uma competência administrativa para o bibliotecário universitário contemporâneo. Informação@ Profissões, Londrina, v. 2, n. 2, p. 119-133, 2013.

TOFFLER, A. A empresa flexível. Rio de Janeiro: Record, 1985.

VANDERSTRAETEN, R. Parsons, Luhmann and the Theorem of Double Contingency. Journal Of Classical Sociology, London, v. 2, n. 1, p.77-92, mar. 2002.

VIZEU, F. Ação comunicativa e estudos organizacionais. RAE, São Paulo: Unicenp v. 45, n. 4, 2005, p. 10-21.

VIZEU, F. Algumas Contribuições da Teoria da Ação Comunicativa para a área de organizações. In: Encontro da Associação Nacional de Pós-graduaçãa e Pesquisa em Administração, 27, 2003. Anais eletrônicos... Atibaia: ANPAD, 2003. Disponível em: <http://www.anpad.org.br/admin/pdf/enanpad2003-teo0106.pdf>. Acesso em: 28 maio 2018.

\section{COMMUNICATIVE COMPETENCE IN THE DISCURSIVE ADMINISTRATION OF ORGANIZATIONS}

\section{ABSTRACT}

Introduction: We discussed the discursive approach of the management of organizations, a science that is based on rational choices of ends and means, but which can (and should) have elements of criticism. Objectives: We aim to develop a discursive approach of management to rethink the theoretical foundations and also to build references for a humanistic and effective management. Methodology: We use 
the methodological counterpoint between Habermas's Theory of Communicative Action and Luhmann's Systems Theory to highlight the potential of the participants' discourse among themselves and the environment. Results: The possibilities of communicative action within the systems are demonstrated through language and argumentation and, in particular, problematization and learning in the organizations - that are part of the communicative competence. For the argumentation, it is necessary volition and intentionality, but also the communicative competence, that allow the crucial rational reconstruction to the development of the discursive administration. Conclusions: we deepen the discussion of the discursive administration and we identify reconstructive exits for this practice in favor of the humanization of the organizations. Discursive competence is based on the use of language and communication that creates links through understanding and agreements and firms the discourse as a special form of interaction. The communicative competence integrates language, gestures and rituality.

Descriptors: Discursive Administration. Communicative Competence. Learning. Rational Reconstruction.

\section{LA COMPETENCIA COMUNICATIVA EN LA ADMINISTRACIÓN DISCURSIVA DE ORGANIZACIONES}

\section{RESUMEN}

Introducción: Se discute el enfoque discursivo de la administración de las organizaciones, una ciencia que se basa en elecciones racionales de fines y de medios, pero que puede (y debe) tener elementos de crítica. Objetivos: Desarrollar un enfoque discursivo de la administración para desplazar los fundamentos teóricos y construir referencias para una gestión humanista y eficaz. Metodología: Se parte del contrapunto metodológico entre la Teoría del Agir Comunicativo de Habermas y la Teoría de Sistemas de Luhmann para evidenciar el potencial del discurso de los participantes de los sistemas entre sí y con el entorno. Resultados: Se evidencian las posibilidades del agir comunicativo dentro de los sistemas a través del lenguaje y de la argumentación $y$, en particular, la problematización y el aprendizaje en las organizaciones que componen la competencia comunicativa. Para la argumentación es necesario voluntad e intencionalidad, pero también la competencia comunicativa, que posibilitan la reconstrucción racional necesaria para el desarrollo de la administración discursiva. Conclusiones: La discusión de la administración discursiva es profundizada y identificamos salidas reconstructivas para esa práctica en favor de la humanización de las organizaciones. La competencia discursiva se fundamenta en el uso del lenguaje y en la comunicación que crea vínculos mediante entendimiento y acuerdos además de firmar el discurso como una forma especial de interacción. La competencia comunicativa integra lenguaje, gestos y rituales.

Descriptores: Administración Discursiva. Competencia Comunicativa. Aprendizaje. Reconstrucción Racional.

Recebido: 04.03.2018

Aceito: 31.05 .2018 